\title{
To the problem 6 of emplacement of triangular geometric net on the sphere
}

\author{
Vladimir Travush ${ }^{1}$, Vasilij Antoshkin ${ }^{2,}$, Irina Erofeyeva $^{2}$ \\ ${ }^{1}$ RAABS, BolshayaDmitrovka, 24,Moscow,107031, Russia \\ ${ }^{2}$ Mordovian State University, Bolshevistskaya, 68, Saransk,430005, Russia
}

\begin{abstract}
Thesphere creates the minimal surface of enclosing structures and has unique resource saving qualities which makes it indispensable in the construction of "smart buildings». One of the methods of formation of triangular networks in the sphere was investigated. Conditions of the problem of locating a triangular network in the area were established. The evaluation criterion of solution effectiveness of the problem is the minimum number of type-sizes of dome panels, the possibility of preassembly and pre-stressing. The solution of the problem of the triangular network emplacement in a compatible spherical triangle on the sphere variant was provided. The problem of the emplacement of regular and irregular hexagons on the sphere, inscribed in a circles, i.e., flat figures or composed ones of spherical triangles with minimum dimensions of the ribs, has an effective solution in the form of a network, formed on the basis of minimum radii circles, i.e., circles on a sphere obtained by the touch of three adjacent circles whose centers are at the shortest distance from each other. The optimization of triangular geometric network on a sphere on the criterion of minimum sizes of elements can be solved by emplacementin the system the irregular hexagons inscribed in circles of minimal sizes, the maximum of regular hexagons.
\end{abstract}

\section{Introduction}

The sphere creates the minimal surface of enclosing structures and has unique resource saving qualities, which makes it indispensable in the construction of «smart buildings». The problem of the emplacement of regular and irregular hexagons on the sphere, inscribed in a circles, i.e., flat figures or composed ones of spherical triangles (See Figure 1) with minimum dimensions of the ribs, has an effective solution in the form of a network, formed on the basis of minimum radii circles, i.e., circles on a sphere obtained by the touch of three adjacent circles whose centers are at the shortest distance from each other. [1-3, 58].However, sometimes there is a possibility of emplacement of two evenly alternating rows of regular hexagons, starting from the equator (Figure 1).

The emplacement of the regular hexagons inscribed in circles, is being realized on the example of cutting, shown in figure 1, and its fragment, shown in Figure 2. To solve this problem (Figure 2), the spherical right triangle $\mathrm{O}_{1} \mathrm{KO}_{2}$ and spherical triangles $\mathrm{O}_{1} \mathrm{GK}$ and

${ }^{*}$ Corresponding author: antovd@mail.ru 
$\mathrm{O}_{2} \mathrm{GK}$ with the parties-arcs, are equal, respectively, to the radii $r_{1}$ and $r_{2}$ need to be considered. There is a rectangular spherical triangle with internal corners of 90 and 60 degrees and a leg arch, equal $a$. It is required to determine sizes of radii $\rho_{1}$ and $\rho_{2}$ between the $\mathrm{O}_{11}, \mathrm{O}_{12}$ and $\mathrm{O}_{2}$ centers of circles and, thus, position of all centers of circles of the first two rows of hexagons will be defined.

To determine the centers of regular hexagons of unequal radii of the first two rows, some additional requirements for the location of their circles are entered. At first, substituting hat the circles cross each other at two points and then they, respectively, might be able to fit regular hexagons. Secondly, it is not considered the influence of the first condition of the further complication of builds.

\section{To the problem 6 of emplacement of triangular geometric net on the sphere}

Previously the parameters in this spherical triangle of $\mathrm{O}_{1} \mathrm{KO}_{2}$ were determined. It is given that the interior angles of a triangle $A=30^{\circ}, B=60^{\circ}, \mathrm{O}_{1} \mathrm{G}=r_{1}, \mathrm{GO}_{2}=r_{2}, \mathrm{O}_{1} \mathrm{~K}=$ $=b=b_{1}+b_{2}$, where $r_{1}$, and $r_{2}$-are the radii of the circles describing the hexagons of the first and second series in polar angle; $b_{1}$ and $b_{2}$ - are the legs of the rectangular spherical triangles in the form of polar angles; $a$ and $2 c$ - side hexagons in the form of polar angles; $A, B$, and $C$ and $D$ - respectively, interior angles on the sphere for spherical hexagons, inscribed in circumferences of the first series.

Using the known expressions Napier [4,14] for the sides and corners of a rectangular spherical triangles $\mathrm{O}_{1} \mathrm{GL}$ and $\mathrm{KGL}$, it's gotten

$$
\begin{gathered}
C=90^{\circ}-D, \\
\sin 30^{\circ} \sin r_{2}=\sin c, \\
\cos C=\frac{\operatorname{tg} c}{\operatorname{tg} r_{2}} \\
\sin 2 c \sin D=\sin b, \\
\sin 30^{\circ} \sin r_{1}=\sin b .
\end{gathered}
$$

From triangles $\mathrm{O}_{1} \mathrm{GK}$ and $\mathrm{O}_{2} \mathrm{GK}$ the magnitude of $\mathrm{b}$ and the desired radii $r_{1}$ and $r_{2}$ will be found

$$
\cos r_{1} \cos b+\sin r_{1} \sin b \cos 30^{\circ}=\cos ^{2} r_{2}+\sin ^{2} r_{2} \cos 60^{\circ} .
$$

Do the changing of system of equations using the formulas $(1,2)$ of spherical trigonometry [14],

$$
\begin{gathered}
0.5 \sin r_{2}=\sin c, \\
\sin D=\frac{\operatorname{tg} c}{\operatorname{tg} r_{2}} ; \\
\sin 2 c \frac{\operatorname{tg} c}{\operatorname{tg} r_{2}}=\sin 30^{\circ} \sin r_{1} ;
\end{gathered}
$$


a

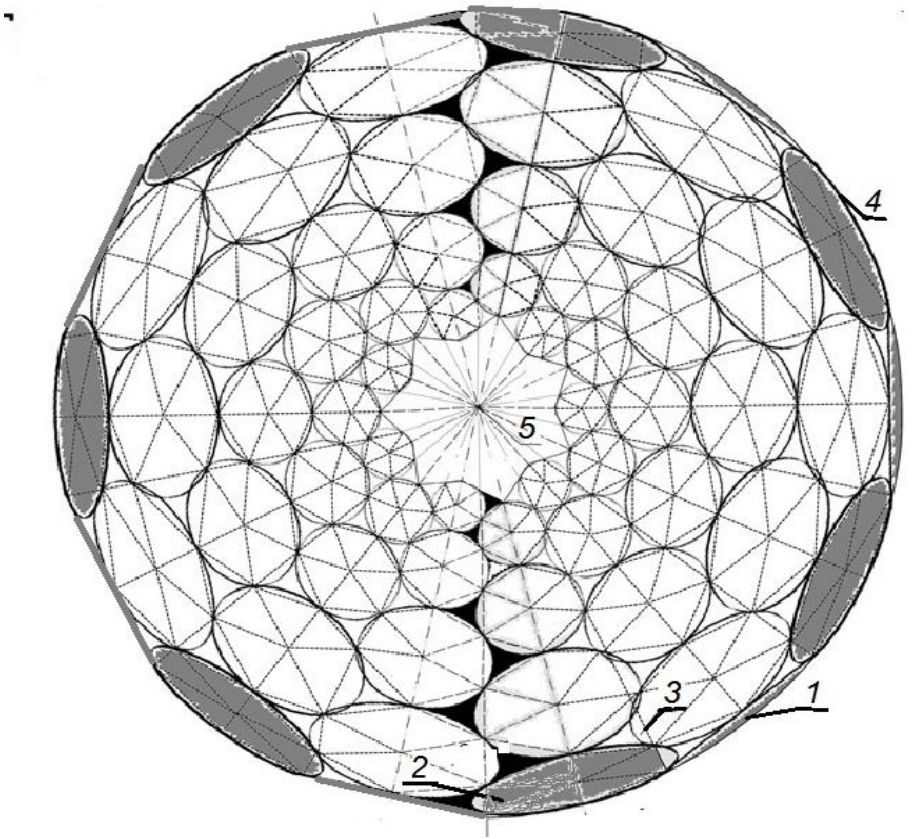

b

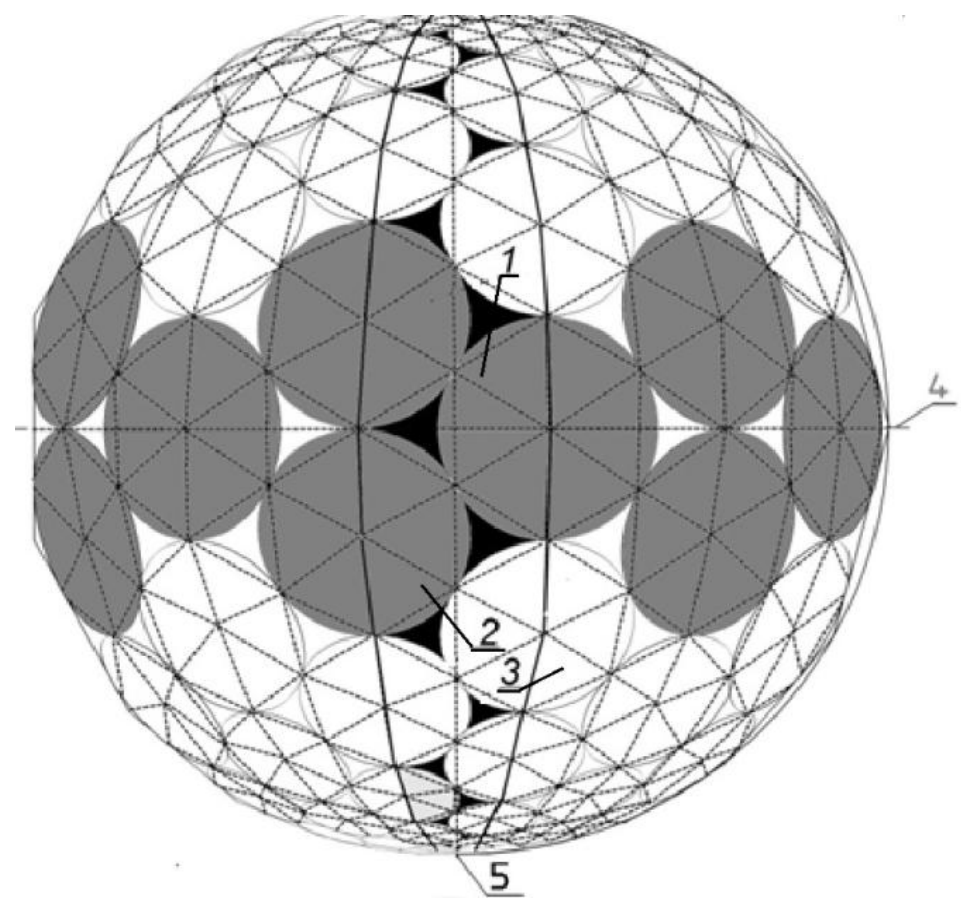

Fig.1.Geometricnetworkonasphereofhexagons, inscribed in circumferences, based on compatibles phericaltriangles(segments) $\mathrm{b}-90-90^{\circ}$ : a - side view; $\mathrm{b}$ - top view; 1 - hexagons(regular hexagons gray) of the first and second number of internal $90^{\circ}$ degree angles; 3 - too third row, respectively; 4 the line of the equator; 5 - point of zenith. 
From where it's gotten

$$
\begin{gathered}
2 \operatorname{tg} c \sin 2 c=\sin r_{1} \operatorname{tg} r_{2} ; \\
4 \sin ^{2} c=\sin r_{1} \operatorname{tg} r_{2} ; \\
\operatorname{ctg} r_{2} \sin ^{2} r_{2}=\sin r_{1} ; \\
\sin r_{2} \cos r_{2}=\sin r_{1} ;
\end{gathered}
$$

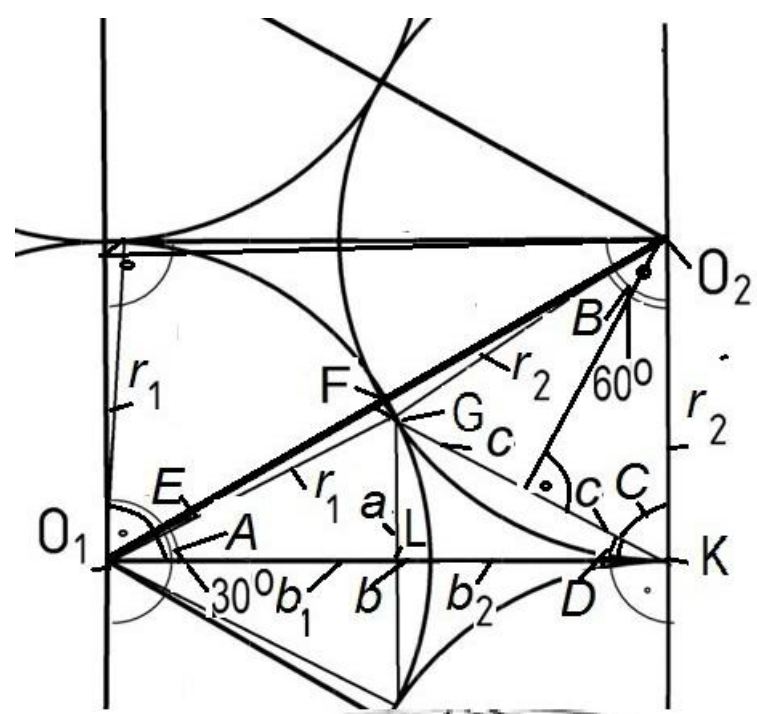

Fig.2.Determination of the position of the center $\mathrm{O}_{2}$ of the hexagons of unequal radii in the spherical triangle $b-90-90^{\circ}$.

The ratio (4)will be put in the first equation (3)

$$
\begin{aligned}
& \sqrt{1-\sin ^{2} r_{2} \cos ^{2} r_{2}} \cos \mathrm{b}+\sin r_{2} \cos r_{2} \sin \mathrm{b} \cos 30^{\circ}= \\
& =\cos ^{2} r_{2}+\cos 60^{0} \sin ^{2} r_{2} \text {; } \\
& \cos b \sqrt{1-\frac{1}{1+\operatorname{tg}^{2} r_{2}} \frac{1}{1+\operatorname{ctg}^{2} r_{2}}}+\sin b \cos 30^{0} \sqrt{\frac{1}{1+\operatorname{tg}^{2} r_{2}} \frac{1}{1+\operatorname{ctg}^{2} r_{2}}}=\frac{1}{1+\operatorname{tg}^{2} r_{2}}+\frac{0.5}{1+\operatorname{ctg}^{2} r_{2}} ; \\
& \cos b \sqrt{1-\frac{1}{1+\operatorname{tg}^{2} r_{2}} \frac{\operatorname{tg}^{2} r_{2}}{1+\operatorname{tg}^{2} r_{2}}}+\sqrt{\frac{1}{1+\operatorname{tg}^{2} r_{2}} \frac{\operatorname{tg}^{2} r_{2}}{1+\operatorname{tg}^{2} r_{2}}} \sin b \cos 30^{\circ}=\frac{1}{1+\operatorname{tg}^{2} r_{2}}+\frac{0.5 \operatorname{tg}^{2} r_{2}}{1+\operatorname{tg}^{2} r_{2}} ; \\
& \cos b \sqrt{\left(1+\operatorname{tg}^{2} r_{2}\right)\left(1+\operatorname{tg}^{2} r_{2}\right)-\operatorname{tg}^{2} r_{2}}+\operatorname{sinb} \cos 30^{0} \\
& \operatorname{tg} r_{2}=1+0.5 \operatorname{tg}^{2} r_{2} \\
& \cos b \sqrt{\left(1+\operatorname{tg}^{2} r_{2}\right)\left(1+\operatorname{tg}^{2} r_{2}\right)-\operatorname{tg}^{2} r_{2}}= \\
& =1+0.5 \operatorname{tg}^{2} r_{2}-\operatorname{sinb} \cos 30^{0} \operatorname{tg} r_{2} ; \\
& \cos ^{2} \mathrm{~b}\left(\left(1+\operatorname{tg}^{2} r_{2}\right)\left(1+\operatorname{tg}^{2} r_{2}\right)-\operatorname{tg}^{2} r_{2}\right)= \\
& =\left(1-\operatorname{sinb} \cos 30^{0} \operatorname{tg} r_{2}+0.5 \operatorname{tg}^{2} r_{2}\right)^{2} \text {; }
\end{aligned}
$$


Substitute $x=\operatorname{tg} r_{2}$

$$
\begin{gathered}
\left.\cos ^{2} \mathrm{~b}\left(1+x^{2}\right)^{2}-x^{2}\right)= \\
=\left(1-\sin \mathrm{b} \cos 30^{0} x+0.5 x^{2}\right)^{2} ; \\
\cos ^{2} \mathrm{~b}\left(1+2 x^{2}+x^{4}-x^{2}\right)= \\
=\left(1-2 \operatorname{sinb} \cos 30^{0} x+\sin ^{2} \mathrm{~b} \cos ^{2} 30^{0} x^{2}+\right. \\
\left.+\left(1-\operatorname{sinb} \cos 30^{0} x\right) x^{2}+0.25 x^{4}\right) ; \\
\cos ^{2} \mathrm{~b}+\cos ^{2} \mathrm{~b} x^{2}+\cos ^{2} \mathrm{~b} x^{4}= \\
=1-2 \sin ^{2} \cos 30^{0} x+\sin ^{2} \mathrm{~b} \cos ^{2} 30^{0} x^{2}+ \\
+x^{2}-\sin \mathrm{b} \cos 30^{0} x^{3}+0.25 x^{4} ; \\
\left(\cos ^{2} \mathrm{~b}-0.25\right) x^{4}+\sin \mathrm{b} \cos 30^{0} x^{3}+\left(\cos ^{2} \mathrm{~b}-\sin ^{2} \mathrm{~b} \cos ^{2} 30^{0}-\right. \\
\text { 1) } x^{2}+2 \sin b \cos 30^{0} x+\cos ^{2} \mathrm{~b}-1=0 .
\end{gathered}
$$

\section{Results}

Byaccepting $b=20^{0}$, it's gotten to

$$
\begin{gathered}
0.63302222156 x^{4}+0.296198132726 x^{3}-0.20471111227089 x^{2} \\
+0.59239626545 x-0.1169777784405=0 .
\end{gathered}
$$

Where from the relation

$$
\operatorname{tgr}_{2}=0.20582743305806134, r_{2}=11.630615 .
$$

From triangle $\mathrm{O}_{2} \mathrm{GK}$, expressing the cosine of the angle $\mathrm{c}$

$$
\sin c=0.5 \sin r_{2}, c=5.78527776^{0} .
$$

All values in the expression (3) are determined, excepting the polar angle of the radius $r_{1}$.Thus, the radius of the second circle will be determined from the Equation(4).

$$
\sin r_{2} \cos r_{2}=\sin r_{1} .
$$

From where it will be received $r_{1}=11.388580819^{0}$.

To solve the equation (6) the free software Sclab 5.4.1 was used - The free platform for Numerical Computation (analogue Matlab) [15].

From figure 2 it is seen that the optimal triangular network on the sphere is obtained if these are right spherical triangles hexagons inscribed in circles of the smallest radius [1] and placed in the first two rows are compatible spherical triangles sphere $b-90-90^{\circ}$.

For a given position of the center of the first rows of hexagons inscribed in a circle, the angles change, and hence, the optimization are possible only for centered hexagons centered $\mathrm{O}_{3}$, andfurther[8, $\left.9,16-22\right]$. 


\section{Conclusions}

These solutions allow to realise the algorithms of approximation the triangular geometric network with the maximum number of regular hexagons and prepare options for optimization of spherecutting.

\section{References}

1. V.D. Antoshkin, V.T. Erofeev, V.I. Travush, V.I. Rimshin, V.L. Kurbatov, Modern Applied Science 3, 46-50 (2015)

2. V. D. Antoshkin, Regional architecture and engineering 3(24), 112-121 (2015)

3. V.D.Antoshkin, S.S. Gudozhnikov, O.I. Perfilieva, I.V. Erofeeva, Proceedings of the Thirteenth International scientific-technical conference 12(2), 4-15 (2014)

4. V.D. Antoshkin., V.I. Nikonov, Fundamental research 11-8, 1669-1673 (2014)

5. V.D. Antoshkin, A.G. Konovalov, Ogarev-Online 13(54), 6-9 (2015)

6. V.D.Antoshkin, G.V. Kurbakov, V.S. Bochkin, StredoevropskyVestnik pro Vedu a Vyzkum 83, 1 (2015)

7. D.V. Alekseevskii, E.B. Vinberg, D.I. Solodovnikov, Geometry of spaces of constant curvature. Fundamental Directions (VINITI, 1998)

8. V.D. Antoshkin, V.G. Kurganski,StredoevropskyVestnik pro Vedu a Vyzkum 83, 2 (2015)

9. V.T. Erofeev, O.V.Startsev, V.D. Antoshkin, S.S. Gudozhnikov, E.G. Smolkin, I.V. Boldin, A.Y. Makhankov, Basic research 9-12, 2630-2638 (2014)

10. W. Lienhard, Elem. Math66 (2), 74-82 (2011).

11. V.F. Manukhov, A.S. Turchin, Glossary of geodetic terms: proc. Manual (PublishingMord. Univ., Saransk, 2005)

12. B.V. Miryaev, Regional architecture and engineering 3, 122-125 (2012)

13. A.G. Konovalov, V.D.Antoshkin, Proceedings of the Thirteenth International scientific-technical conference 14(2), 48-53 (2015)

14. G.A.Korn, T.M.Korn, Mathematical Handbook for Scientists and Engineers, 1151 (2000)

15. Software Scilab 5.4.1 - The free platform for Numerical Computation,

16. S. Çarbaş, M. P. Saka, Asian journal of civil engineering 10(1), 97-112 (2009)

17. A. Behzad, M. Hamid, A.Amran, Applied Mechanics and Materials 110-116(39), 956-964 (2012)

18. A. Lopez, I. Puente and M. A. Serna, Proceedings of the international symposium, 2428(6), 639-644 (2002)

19. V. I. Travush, V. D. Antoshkin, , I. V. Yerofeyeva, , D. V. Antoshkin, Team spherical shell, 2564545(2014)

20. V. I. Travush, V. D. Antoshkin, V. T. Erofeyev, S. S. Gudozhnikov, Construction and reconstruction 6(50), 36-48 (2013)

21. V. I. Travush, V. D. Antoshkin, V. T. Erofeev, MATEC, 86 (2016)

22. V. I. Travush, V. D. Antoshkin, V. T. Erofeev, MATEC, 86 (2016) 